\title{
Evaluation of the urban tile in MOSES using surface energy balance observations
}

Article

Accepted Version

Best, M. J., Grimmond, C. S. B. and Villani, M. G. (2006) Evaluation of the urban tile in MOSES using surface energy balance observations. Boundary-Layer Meteorology, 118 (3). pp. 503-525. ISSN 0006-8314 doi:

https://doi.org/10.1007/s10546-005-9025-5 Available at https://centaur.reading.ac.uk/72065/

It is advisable to refer to the publisher's version if you intend to cite from the work. See Guidance on citing.

Published version at: http://dx.doi.org/10.1007/s10546-005-9025-5

To link to this article DOI: http://dx.doi.org/10.1007/s10546-005-9025-5

Publisher: Springer

All outputs in CentAUR are protected by Intellectual Property Rights law, including copyright law. Copyright and IPR is retained by the creators or other copyright holders. Terms and conditions for use of this material are defined in the End User Agreement.

www.reading.ac.uk/centaur 
Central Archive at the University of Reading

Reading's research outputs online 


\title{
EVALUATION OF THE URBAN TILE IN MOSES USING SURFACE ENERGY BALANCE OBSERVATIONS
}

\author{
M. J. BEST ${ }^{1, *}$, C. S. B. GRIMMOND ${ }^{2}$ and MARIA GABRIELLA VILLANI ${ }^{2,3,4}$ \\ ${ }^{1}$ Met Office, Joint Centre for Hydro-Meteorological Research, Maclean Building, Crowmarsh \\ Gifford, Wallingford, Oxfordshire, OX10 8BB, U.K.; ${ }^{2}$ Atmospheric Science Program, \\ Department of Geography, Indiana University, Bloomington, IN 47405, U.S.A.; ${ }^{3} I S A C-$ \\ CNR, Via Gobetti, 101, 40129 Bologna, Italy; ${ }^{4}$ University of Urbino, Environmental Science \\ Faculty, Campus Scientifico Sogesta, 61029 Urbino, Italy
}

(Received in final form 12 August 2005)

\begin{abstract}
The UK Met Office has introduced a new scheme for its urban tile in MOSES 2.2 (Met Office Surface Exchange Scheme version 2.2), which is currently implemented within the operational Met Office weather forecasting model. Here, the performance of the urban tile is evaluated in two urban areas: the historic core of downtown Mexico City and a light industrial site in Vancouver, Canada. The sites differ in terms of building structures and mean building heights. In both cases vegetation cover is less than $5 \%$. The evaluation is based on surface energy balance flux measurements conducted at approximately the blending height, which is the location where the surface scheme passes flux data into the atmospheric model. At both sites, MOSES 2.2 correctly simulates the net radiation, but there are discrepancies in the partitioning of turbulent and storage heat fluxes between predicted and observed values. Of the turbulent fluxes, latent heat fluxes were underpredicted by about one order of magnitude. Multiple model runs revealed MOSES 2.2 to be sensitive to changes in the canopy heat storage and in the ratio between the aerodynamic roughness length and that for heat transfer (temperature). Model performance was optimum with heat capacity values smaller than those generally considered for these sites. The results suggest that the current scheme is probably too simple, and that improvements may be obtained by increasing the complexity of the model.
\end{abstract}

Keywords: Model evaluation, Sensitivity analysis, Surface scheme, Urban energy balance.

\section{Introduction}

Over $50 \%$ of the World's population live in cities, yet urban environments typically are not represented within weather forecasting models (Best, 2005a). Urbanization and associated human activities radically change the

* E-mail: martin.best@metoffice.gov.uk 
surface characteristics of cities, and modifications of the radiative, roughness, thermal, and moisture properties of the urban surface result in distinct urban climates that can differ significantly from natural, unmodified environments. The operational limitations that constrain weather forecast models mean that complex representations of urban areas are not practical. Consequently, simplified solutions have to be found. One such scheme is part of MOSES (Met Office Surface Exchange Scheme) and is implemented within the operational UK Met Office weather forecasting model. This scheme uses a simple canopy representation for urban areas, whereby the available energy at the surface is divided into sensible and latent heat fluxes and heat storage within the canopy; the canopy is then radiatively coupled to the underlying soil (Best, 2005b). The purpose of this study is to evaluate the performance of the Best (2005b) scheme.

Field campaigns and numerical models have both been used in the study of urban climates (Grimmond, 2005; Masson, 2005). Field campaigns provide invaluable information on urban climatic processes and effects in a wide range of settings, though high costs, the time required, and the complexity and diversity of cities around the world make field campaigns difficult to conduct on a regular and systematic basis (Plate, 1999). As a result, the number of available datasets of urban observations is relatively limited (see, for example, Grimmond and Oke, 2002; Arnfield, 2003; Grimmond, 2005). Numerical models allow a detailed analysis of urban meteorology and allow comparisons between existing and future conditions. However, these numerical models need to be carefully evaluated with meteorological observations in order to judge the reliability of the numerical results produced.

Numerical models that have been developed to simulate the urban climate have largely been formulated either at the microscale (building and/or urban canyon) (e.g. Mills, 1997; Arnfield and Grimmond, 1998; Herbert et al., 1998), or at the mesoscale (whole city). Masson (2005) recently reviewed the range of urban schemes that are currently available for use in mesoscale numerical models, which he subdivided into: empirical; vegetation schemes, with or without drag terms, adapted and modified to fit urban canopy physics; and urban canopy schemes that are single (e.g. Masson, 2000) or multi-layered (e.g. Martilli et al., 2002).

Recent work has evaluated the Town Energy Balance model, TEB, of Masson (2000) with observed urban surface radiation and energy balance fluxes and surface temperatures. Results indicate that TEB generally performs well when evaluated with measured local-scale fluxes and temperatures (air, surface) (Masson et al., 2002; Lemonsu et al., 2004). To date, the simpler surface scheme described by Best (2005b) and Essery et al. (2003) has been evaluated only with respect to air temperature and other scalar 
quantities within an environment that is fully coupled to the atmosphere (Best, 2005b).

The aim of this work is to evaluate the Met Office Surface Exchange Scheme (MOSES 2.2; Essery et al., 2003) using directly measured surface energy balance fluxes. MOSES 2.2 employs a tiled representation of heterogeneous surfaces, and treats sub-grid land-cover heterogeneity explicitly (Essery et al., 2003). Nine surface types are recognized, and, among them, the urban surface is represented according to the simple canopy scheme of Best (1998, 2005b). In this study, two 'simple' built sites are considered. The first lies within the historic core of Mexico City (Oke et al., 1999) and the second is a light industrial site in Vancouver, British Columbia (Voogt and Grimmond, 2000). At both sites vegetation cover is less than $5 \%$ of the plan area (Grimmond and Oke, 2002), and this allows the urban tile of MOSES 2.2 to be evaluated most directly. The sites are different, however, in terms of structure and building construction (Masson et al., 2002). Sensitivity analyses are conducted to determine the key parameters needed to model urban climates with MOSES 2.2, and to evaluate how much of the observed differences between these two cities can be represented by these parameters alone.

\section{The Urban Canopy Scheme}

The surface scheme MOSES 2.2 has a tile or mosaic scheme for calculating surface energy exchanges for up to nine surface types (broadleaf trees, needleleaf trees, temperate grass, tropical grass, shrubs, urban, inland water, bare soil, and ice) (Essery et al., 2003). Vertical fluxes are then averaged, using blending height techniques, to give grid-box values (Best and Clark, 2002). The urban tile is explicitly represented using the canopy approach presented in Best $(1998,2005 b)$. Urban areas are represented in a simple way by introducing a canopy that has the thermal properties of urban elements; this canopy is radiatively coupled to the underlying soil scheme that retains the thermal properties of soil (Figure 1). In the absence of snowmelt, the surface energy balance for the urban and the other tiles is:

$$
C \frac{d T_{\mathrm{s}}}{d t}=Q^{*}-Q_{\mathrm{H}}-Q_{\mathrm{E}}-Q_{\mathrm{G}}
$$

where $C$ is the heat capacity, $T_{\mathrm{s}}$ is the temperature (surface skin temperature or canopy layer temperature for vegetated tiles), $Q^{*}$ is the net all-wave radiation

$$
Q^{*}=K^{*}+\varepsilon_{\mathrm{s}} L_{\downarrow}-\varepsilon_{\mathrm{s}} \sigma T_{\mathrm{s}}^{4}
$$



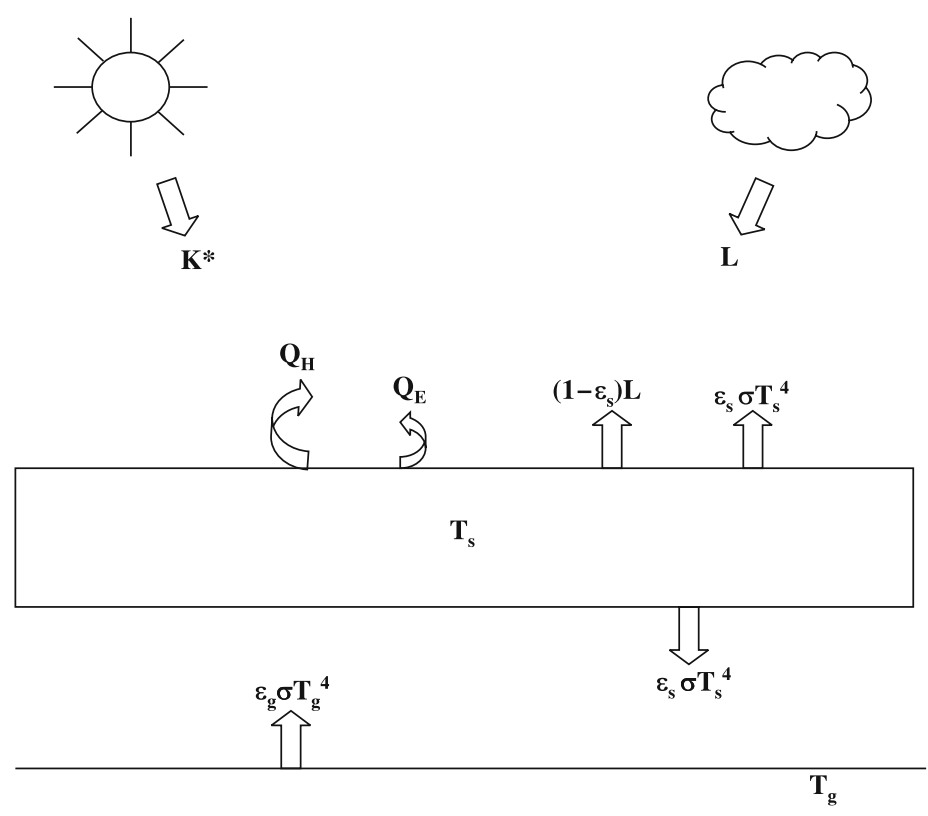

Figure 1. Surface energy balance of urban canopy model.

with $K^{*}$ the net shortwave radiation, $L_{\downarrow}$ the downward longwave radiation, $\varepsilon$ is the emissivity and $\sigma$ the Stefan Boltzmann constant. Note the emissivity of the ground (subscript g) and the surface (s) are assumed to be 1 . The terms $Q_{\mathrm{H}}$ and $Q_{\mathrm{E}}$ are the turbulent sensible and latent heat fluxes respectively, and $Q_{\mathrm{G}}$ is the energy exchange between the canopy and the underlying soil, which is parameterized as (Essery et al., 2003):

$$
Q_{G}=f\left(\varepsilon_{\mathrm{s}} \sigma T_{\mathrm{s}}^{4}-\varepsilon_{\mathrm{g}} \sigma T_{\mathrm{g}}^{4}\right)+(1-f) \frac{2 \lambda}{\Delta z}\left(T_{\mathrm{s}}-T_{\mathrm{g}}\right),
$$

where $f$ is a radiative fraction that depends on the tiles selected, $\lambda$ is the thermal conductivity, and $\Delta z$ and $T_{\mathrm{g}}$ are the thickness and temperature of the top soil layer (for more details, see Essery et al., 2003).

If we consider the traditional energy balance equation for urban areas (Oke, 1988), assuming no advection,

$$
Q^{*}+Q_{\mathrm{F}}=Q_{\mathrm{H}}+Q_{\mathrm{E}}+\Delta Q_{\mathrm{S}}
$$

where $Q_{\mathrm{F}}$ is the anthropogenic heat source (which is neglected within the model) and $\Delta Q_{\mathrm{S}}$ is the net heat storage within the urban area, then this heat storage term

$$
\Delta Q_{\mathrm{S}}=C \frac{d T_{\mathrm{S}}}{d t}+Q_{\mathrm{G}}
$$


is the sum of the heat stored within the canopy and the energy exchange with the heat stored in the underlying soil.

There are relatively few parameters used for the urban tile within MOSES; parameters used include the surface albedo (both for snow-covered and snow-free surfaces), the aerodynamic roughness length $\left(z_{0 \mathrm{~m}}\right)$, and the heat capacity (C) in Equation (1). This means that the scheme is simple and so cannot represent the detailed differences between many cities. In particular, it contains no information about the three-dimensional morphology of buildings.

In addition, the flux of moisture from the urban tile is limited to the evaporation of available water lying on the surface. If the surface is dry, then no evaporation can occur from the urban tile.

\section{Observations}

To assess the model, surface energy balance (SEB) observations are used from two urban areas, the downtown area of Mexico City and a light industrial site in Vancouver (Oke et al., 1999; Grimmond and Oke, 2002). More details are also available in Grimmond and Oke (1999a, b), Voogt and Grimmond (2000), and Masson et al. (2002). These sites are chosen to minimize the role of moisture and vegetation. In both measurement periods there was no rain or snow and at both sites vegetation cover is less than $5 \%$. The land cover characteristics from the average footprint of the turbulent flux measurements are given in Table I. The footprint, determined for each hour of the observation period using the Schmid (1994) source area model, is used as a weighted filter to sample a geographic information system database.

The data required both to run and to evaluate the model are given in Table II. The local-scale surface energy balance measurements used here are conducted within the framework of the traditional energy balance for urban areas (Equation (4)). The terms in (4) are evaluated by

TABLE I

Characteristics of the two urban sites (Grimmond and Oke, 2002).

\begin{tabular}{llllll}
\hline & \multicolumn{4}{l}{ Land cover $($ plan area fractions, in \%) } \\
\cline { 2 - 6 } & Buildings & Impervious & Trees & Grass & Bare soil \\
\hline Vancouver & 51 & 44 & 3 & 2 & 0 \\
Mexico city & 55 & 41 & 1 & 1 & 2 \\
\hline
\end{tabular}




\section{J. BEST ET AL.}

\section{TABLE II}

Observed data used to run and evaluate the surface model (Grimmond and Oke, 1999a; Oke et al., 1999; Voogt and Grimmond, 2000; Masson et al., 2002).

\begin{tabular}{lll}
\hline & Vancouver & Mexico City \\
\hline (a) Observed data used to run the surface model & \\
Mean building height & $6.9 \pm 2.5 \mathrm{~m}$ & $18.4 \pm 6.6 \mathrm{~m}$ \\
$K_{\downarrow}$ & $8 \mathrm{~km}$. south of site & $13 \mathrm{~km}$. south of site \\
$L_{\downarrow}$ & Prata (1996) & Prata (1996) \\
$T_{\mathrm{a}}, q_{\mathrm{a}}$ & Adjusted to $28.5 \mathrm{~m}$ & $28.4 \mathrm{~m}$ \\
$U, V$ & above ground level & above ground level \\
(b) Observed data used to evaluate the model & \\
$Q^{*}$ & Radiometry at $28.5 \mathrm{~m}$. & Radiometry at $28.4 \mathrm{~m}$. \\
$H$ & Eddy covariance & Eddy covariance \\
LE & at 28.5 m. & at $28.4 \mathrm{~m}$ \\
\hline
\end{tabular}

measurements at the top of an atmospheric 'box' (see Figure 2 in Grimmond and Oke, 2002), the height of which extends from the measurement level down to a depth in the ground where there is no net heat exchange over the time period of interest. The grid cell is regarded as homogeneous from the modelling perspective, though from a measurement point of view the area is homogeneous only if the site has sufficient extensive fetch to minimize local-scale advection. The three components, net radiation $\left(Q^{*}\right)$, turbulent sensible $\left(Q_{\mathrm{H}}\right)$, and latent heat fluxes $Q_{\mathrm{E}}$, are measured directly and net heat storage flux $\left(\Delta Q_{\mathrm{S}}\right)$ is determined as the residual of (4). The anthropogenic heat flux $\left(Q_{\mathrm{F}}\right)$ was not determined independently at these sites but it is expected to be small; the primary sources are likely associated with vehicles and therefore peak in the morning and afternoon rushhour periods. The lack of inclusion of this term will, likely, result in a smaller estimate than the actual $\Delta Q_{\mathrm{S}}$. To ensure that the measurement 'box' is representative of the integrated local scale, horizontal length scales of approximately $10^{2}-10^{4} \mathrm{~m}$, instruments were mounted high enough above the surface to obtain an integrated or local-scale response (Oke et al., 1989; Grimmond and Oke, 1999a, b, 2002).

Data were collected for Mexico City (here referred to as Me93) for a seven-day period during the dry season in December 1993 (Oke et al., 1999). The study site is located in the historic core of the city in an area of mainly institutional and commercial buildings. Based on an inventory of material within a radius of $500 \mathrm{~m}$ around the measurement tower, walls are made of concrete or stone, with roofs of concrete, tar, sheets of metal, 

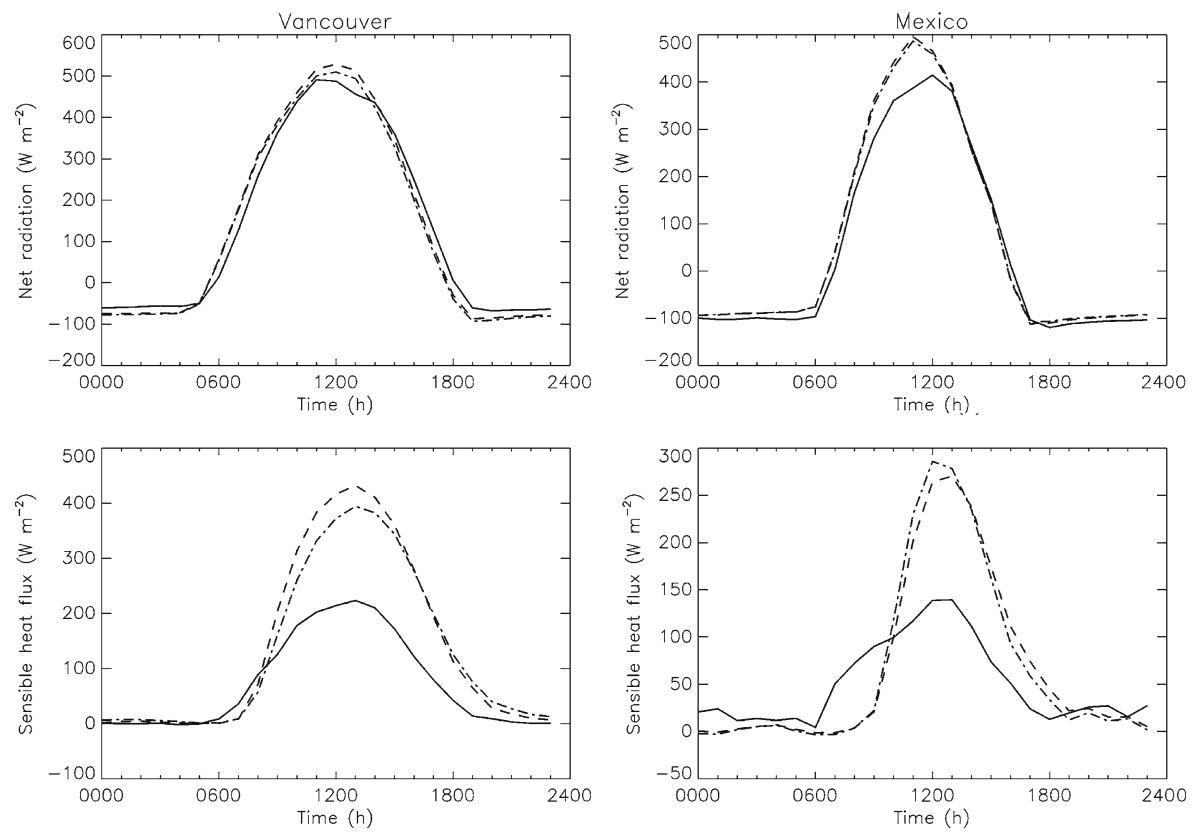

Figure 2. Observed and modelled, using standard parameters (see text), net all-wave radiation and turbulent sensible heat fluxes for Vancouver and Mexico City. Note $y$-axes are different between figures. Solid line: observed flux; dashed line: modelled flux with default parameters; dashed dot line: modelled flux with observed values for parameters.

or tile. Building walls and roofs are usually grey or brown. The roads are paved with concrete or asphalt, or surfaced with tiles, cobbles or flagstone (Masson et al., 2002). The mean tree canopy height is about $10 \mathrm{~m}$.

For Me93, the micrometeorological equipment was mounted at $28.4 \mathrm{~m}$ above the ground. Turbulent fluxes were measured using eddy covariance techniques and radiometry was used to determine $Q^{*}$ (full details in Oke et al., 1999). Incoming solar radiation, $K_{\downarrow}$, an input needed for MOSES 2.2, was not measured in the observational campaign, but was obtained from a site at the Institute of Geophysics, Universidad Nacional Autonoma de Mexico (approximately $13 \mathrm{~km}$ south of the Me93 site). Incoming longwave radiation, $L_{\downarrow}$, was not measured but calculated using observed air temperature and humidity following the method of Prata (1996).

Data were collected for 15 days in August 1992 at a light industrial site in Vancouver B.C. (hereafter referred to as V192), during an extended period of drought. The area is characterized by flat-roofed buildings one to three stories in height used for light industry and warehouses. Most buildings are made of concrete, and roads and pathways are made of asphalt and concrete. In Vancouver the equipment was mounted at $28.5 \mathrm{~m}$ above the ground, and, as in Mexico City, consisted of eddy covariance-based 
instrumentation and radiometry. The Canadian Atmospheric Environment Service measured $K_{\downarrow}$ at the Vancouver International Airport (approximately $8 \mathrm{~km}$ south of the V192 site). The Prata (1996) method was used to calculate $L_{\downarrow}$.

\section{Results}

\subsection{Net all-wave radiation and Sensible heat fluxes}

In this study, an exact correspondence between measured and modelled fluxes is not to be expected since other sources of heat, such as anthropogenic heat flux, are not considered in the model and advection is not considered in the model or measurements (see also Masson et al., 2002). MOSES 2.2 is run in stand-alone format so there is no advective feedback from the surrounding grid cells (as would be the case when coupled to the Unified Model). Thus, this intercomparison differs from that of Best (2005b) where the evaluation is of the coupled system.

The results for net radiation and sensible heat flux from MOSES 2.2 with its standard set of parameters for the urban tile (Table III) are shown in Figure 2, along with the observed values. Also in Figure 2 are the results from MOSES 2.2 when the surface albedo and aerodynamic roughess length for the urban tile are set to appropriate values for the sites (Table III). The albedo is the weighted average of the roof, wall and road albedos (Masson et al., 2002). There is a slight improvement in sensible heat flux at the Vancouver site from using the observed parameters, but the net radiation and the heat and moisture fluxes at the Mexico city site are similar regardless of whether observed parameters or model default values are used.

Changes to the roughness length have an impact on the simulation, noting that the default value of urban roughness length in the model is $1.0 \mathrm{~m}$. At the Vancouver site it is closer to $0.35 \mathrm{~m}$ (Grimmond and Oke, 1999b), and a change in roughness length between these values leads to the observable differences in the sensible heat flux. However, at the Mexico City site the roughness length of $2.2 \mathrm{~m}$ does not represent as significant a change from the urban canopy scheme's default value (due to the logorithmic behaviour of the roughness length), hence the small changes to the modelled fluxes at the Mexico City site. These results provide insight into potential problems of using default values within the urban canopy scheme when applied globally.

The simulations shown in Figure 2 indicate a significant overestimation in the sensible heat flux. One possible reason for the high values may relate to the ratio of the roughness lengths for heat and momentum that is used 
EVALUATION OF THE URBAN TILE IN MOSES

TABLE III

Values assigned to parameters for model runs.

\begin{tabular}{|c|c|c|c|c|}
\hline & V192 & Me93 & $\begin{array}{l}\text { MOSES } \\
\text { default }\end{array}$ & $\begin{array}{l}\text { Sensitivity } \\
\text { tests }\end{array}$ \\
\hline Albedo & 0.19 & 0.20 & 0.18 & - \\
\hline Roughness length for momentum $(\mathrm{m})\left[z_{0 \mathrm{~m}}\right]$ & 0.35 & 2.2 & 1.0 & - \\
\hline$z_{0 \mathrm{t}} / z_{0 \mathrm{~m}}$ & $10^{-7}$ & $10^{-7}$ & 0.1 & $10^{-1}$ to $10^{-9}$ \\
\hline $\begin{array}{l}\text { Heat capacity }\left(\mathrm{MJ} \mathrm{m}^{-2} \mathrm{~K}^{-1}\right) \\
\text { Two fraction model (roof and canyon) }\end{array}$ & 0.28 & 0.28 & 0.28 & 0 to 0.28 \\
\hline Albedo - roof fraction & 0.12 & 0.20 & - & - \\
\hline Albedo - canyon fraction & 0.26 & 0.20 & - & - \\
\hline Roughness length for momentum (m) $\left[z_{0 \mathrm{~m}}\right]$ & 0.35 & 2.2 & - & - \\
\hline$z_{0 \mathrm{t}} / z_{0 \mathrm{~m}}$ & $10^{-7}$ & $10^{-7}$ & - & - \\
\hline Heat capacity $\left(\mathrm{MJ} \mathrm{m}^{-2} \mathrm{~K}^{-1}\right)-$ roof fraction & 0.053 & 0.017 & - & - \\
\hline Heat capacity $\left(\mathrm{MJ} \mathrm{m}^{-2} \mathrm{~K}^{-1}\right)$ - canyon fraction & 0.28 & 0.28 & - & - \\
\hline
\end{tabular}

in the urban canopy scheme. The standard value for this ratio is 0.1 , which is the value that is typically used for all types of surface. To investigate the sensitivity of the model results to this ratio of the roughness lengths, MOSES 2.2 has been operated with ratios varying from $10^{-1}$ to $10^{-9}$ for the urban surface (Figure 3). The size of the sensible heat flux decreases when the ratio of the roughness length for heat to the roughness length for momentum $\left(z_{0 \mathrm{~m}}\right)$ is reduced. The closest relation between modelled and observed results in terms of magnitude of the sensible heat flux for both sites is given with a ratio between $10^{-5}$ and $10^{-7}$ (a value of $10^{-7}$ is used in the subsequent simulations reported herein). This is in good agreement with values of this ratio that have been observed within cities (e.g. Voogt and Grimmond, 2000).

Reducing the ratio of the roughness lengths for heat and momentum indicates that heat transfer away from the surface is less efficient, resulting in higher surface temperatures, and having an impact on the net radiation through the longwave radiation emitted at the surface. This can be seen clearly in Figure 3 where the reduction in the ratio also reduces the net radiation. For Mexico City this does not have a detrimental effect on the net radiation compared to the observed values, but the simulation for Vancouver does increase the error in the magnitude.

The canopy representation used in this modelling study has only one parameter that could be considered to be "tuneable", or changed in such a way as to obtain a good fit to the data. This is the effective heat capacity of the canopy and is representative of the general heat storage of the 

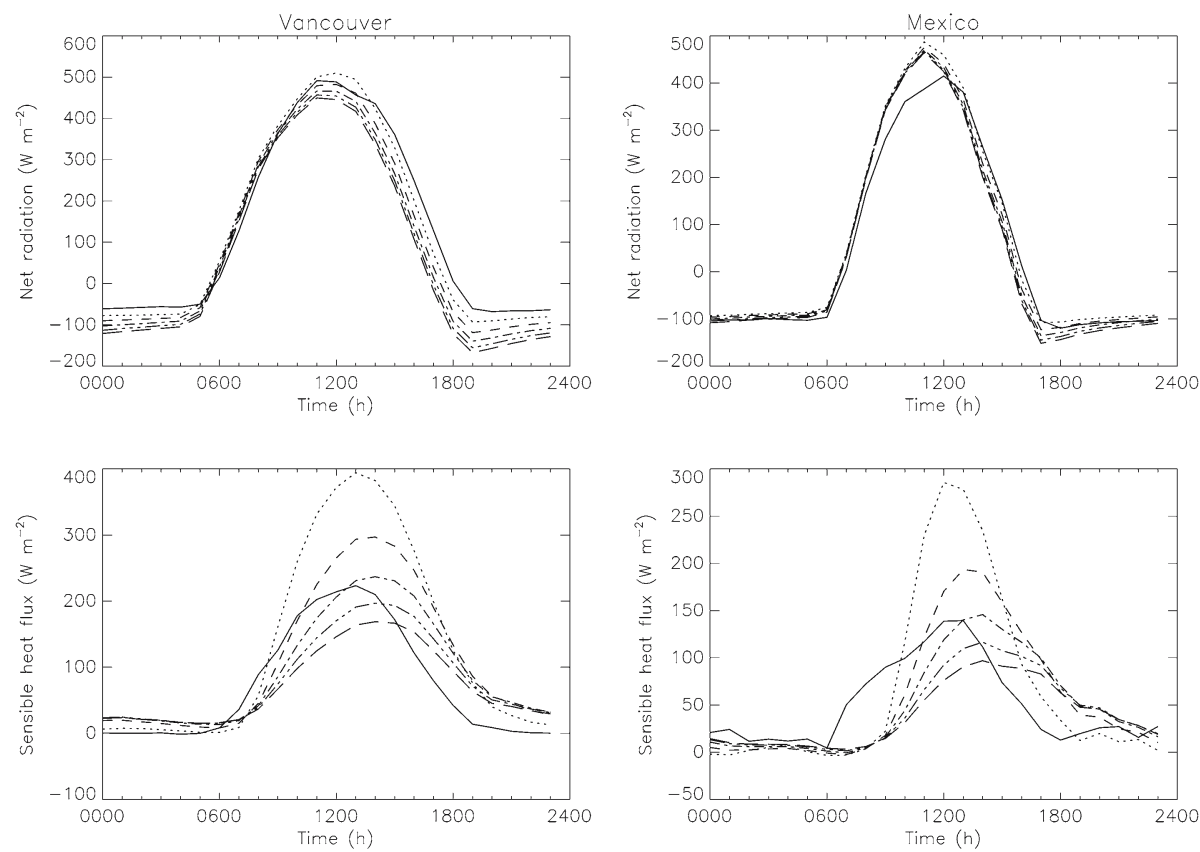

Figure 3. Sensitivity test to changes in roughness length for heat $(\mathrm{m})$. Solid line: observed flux, dotted line: $z_{0 \mathrm{t}} / z_{0 \mathrm{~m}}=10^{-1}$, short dashed line: $z_{0 \mathrm{t}} / z_{0 \mathrm{~m}}=10^{-3}$, dashed dot line: $z_{0 \mathrm{t}} / z_{0 \mathrm{~m}}=$ $10^{-5}$, dashed treble dot line: $z_{0 \mathrm{t}} / z_{0 \mathrm{~m}}=10^{-7}$, long dashed line $z_{0 \mathrm{t}} / z_{0 \mathrm{~m}}=10^{-9}$.

site as a whole. Given that the morphology of the urban surface is not considered in the canopy scheme, this parameter is not well defined and cannot be measured. To evaluate the impact of changing this parameter, MOSES 2.2 was operated with the heat capacity for the urban tile set to $0,0.1$, and $0.28 \mathrm{MJ} \mathrm{m}^{-2} \mathrm{~K}^{-1}$ (its default value), respectively, and a value determined by a weighted sum of the heat capacities for the canyon fraction and the roof fraction (Table III). The heat capacity for the canyon fraction (as defined by the impervious fraction) was taken to be the model default value, whilst the heat capacity for the roof fraction (as defined by the building fraction) was calculated from the materials used in the construction of the roof (Masson et al., 2002). The results of this sensitivity study are shown in Figure 4.

The impact of changing the heat capacity in the urban canopy scheme is two fold. First, it changes the magnitude of the sensible heat flux, and second, it changes the phase. It is clear from Figure 4 that it is not possible to select a value of the heat capacity that will give the correct amplitude of the sensible heat flux and also the correct phase compared to the observed values. This suggests that the simple canopy representation of urban areas that is used here is not sufficient to accurately represent the energy balance at the two sites. 

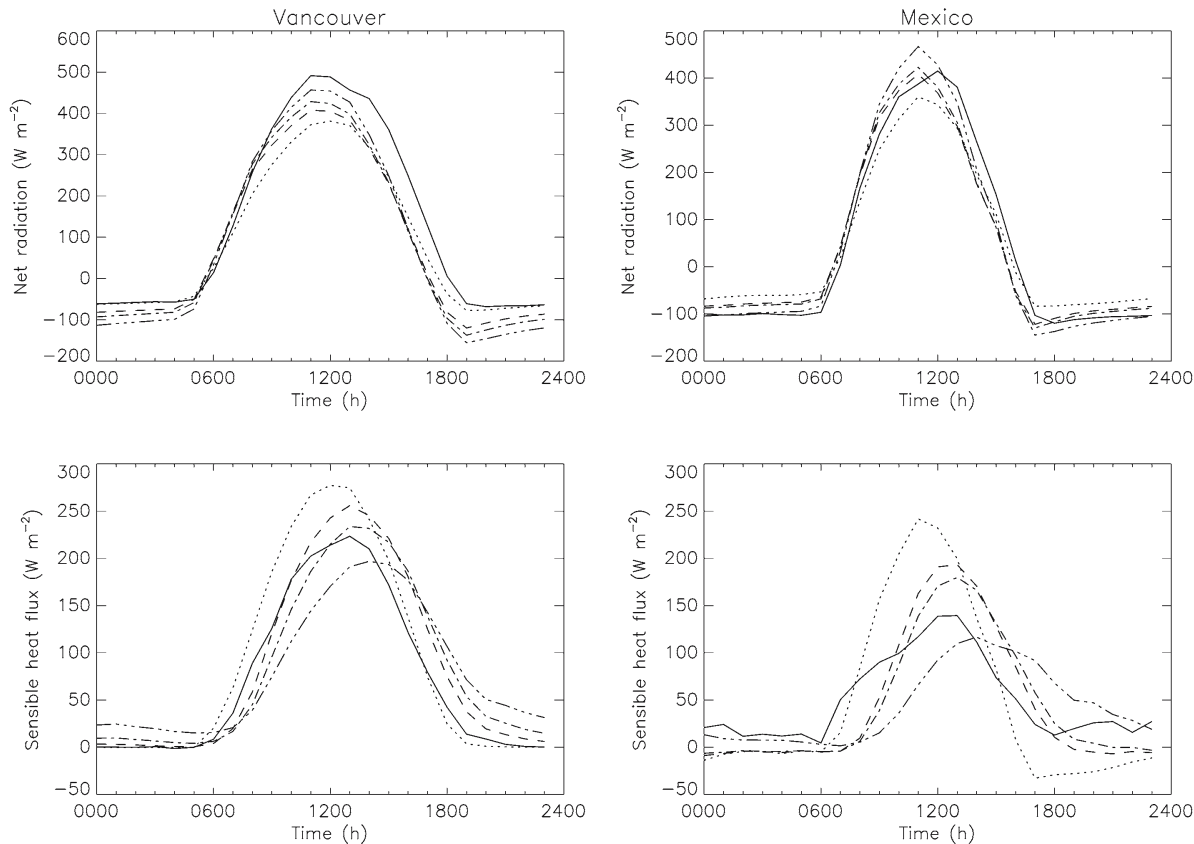

Figure 4. Sensitivity to changes in the heat capacity $\left(\mathrm{J} \mathrm{K}^{-1} \mathrm{~m}^{-2}\right)$. Solid line: observed flux; dotted line: heat capacity $=0.0$; dashed line: heat capacity $=10^{5} \mathrm{~J} \mathrm{~K}^{-1} \mathrm{~m}^{-2}$; dashed dot line: heat capacity $=$ weighted average of building materials, dashed treble dot line: heat capacity $=2.8 \times 10^{5} \mathrm{~J} \mathrm{~K}^{-1} \mathrm{~m}^{-2}$.

As the heat capacity is reduced, the surface temperature rises, which leads to larger turbulent fluxes. This in turn increases the amount of longwave radiation emitted from the surface, which reduces the net radiation (Figure 4). So, if the heat capacity was set in order to give the correct phase in the sensible heat flux, then the resulting surface temperature would give a magnitude of the sensible heat flux that is too large and a magnitude of the net radiation that is too small. Again this shows that the simple canopy representation cannot accurately model the two sites.

As a first attempt to address the problems with the simple canopy representation, the urban fraction was split into a roof fraction and a canyon fraction. This split is based upon the fractions for buildings and impervious surfaces, respectively (from Masson et al., 2002). The canyon fraction was assigned the model default value for heat capacity and for the albedo the weighted average of the street canyon facets (Table III). For the roof fraction, the albedo was set to the value appropriate for the roof and the heat capacity was set to the value calculated from the materials used in the construction of the roof (Masson et al., 2002). This gives the roof a lower heat capacity than that used for the canyon fraction (Table III). 

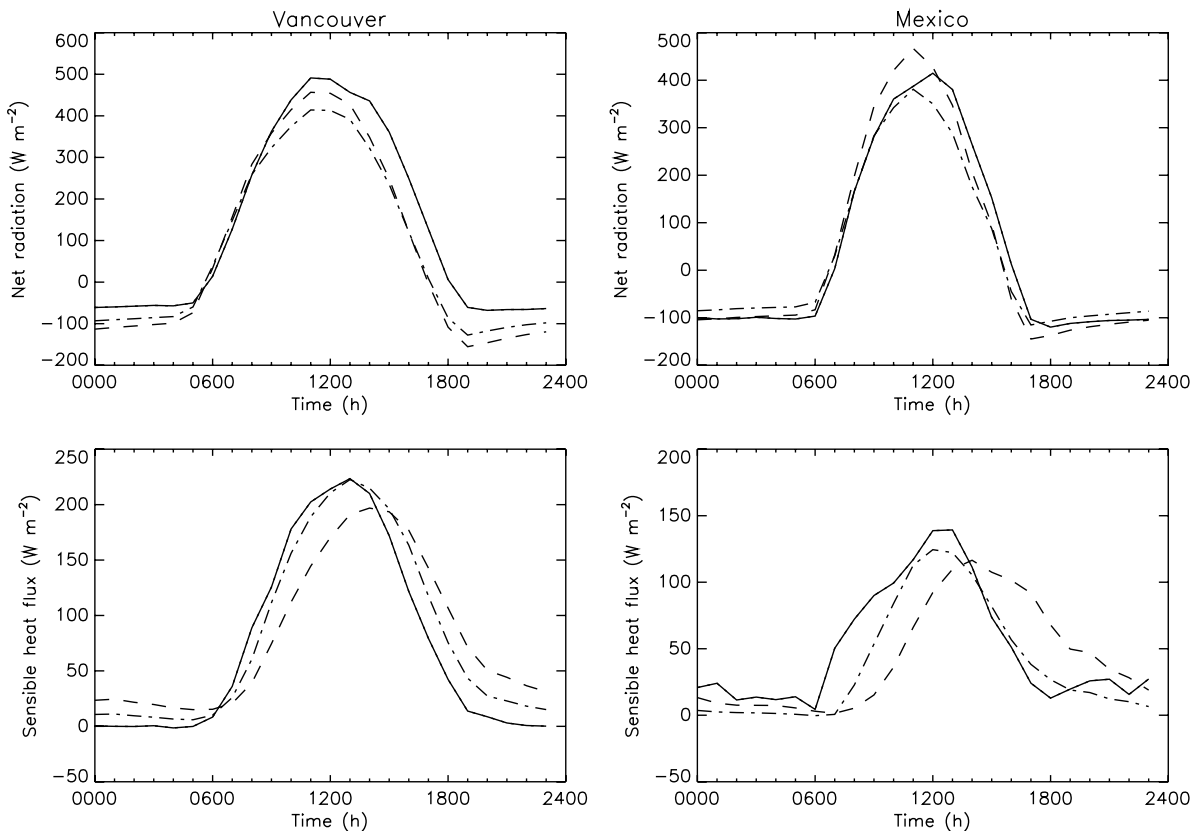

Figure 5. Effect of modelling roofs and canyon space separately compared to modelling them as one surface. Solid line: observed flux; dotted line: standard one urban tile; dashed dot line: roof and canyon tiles.

The results from splitting "urban" into a roof fraction and a canyon fraction are shown in Figure 5, along with the previous results using only the simple canopy representation. Including the roof fraction has a positive impact on how well MOSES 2.2 simulates the sensible heat flux at both locations, with both the amplitude and the phase in better agreement with the observations. At the Mexico City site, including the roof fraction also has a positive impact on the net radiation, but this is not true for the Vancouver site. At this site the net radiation, which was underestimated, now has an even smaller magnitude.

At the Vancouver site, while there is a good agreement between modelled and measured data in terms of the amplitude of the sensible heat flux, the values from MOSES $2.2 \mathrm{lag}$ the observations (i.e., there is a phase error). This does not appear to be the case at the Mexico City site, although on average there is an underestimation of the sensible heat flux at dawn. This period corresponds to a time of relatively high vehicle traffic within Mexico City, which is not represented within MOSES 2.2. Therefore, the underestimation of the sensible heat flux during this period may be due to an anthropogenic heat source. However, there is a similar period of traffic activity, and thus anthropogenic heating, during the evening, which, if 
taken into account, would lead to a phase error in the modelled sensible heat flux.

The canopy scheme presented here has no knowledge of the geometry of the urban environment, i.e., it models all urban areas in exactly the same way. However, it is possible to enhance the urban canopy scheme so that some geometry can be introduced into the simulations presented here. This enhancement to MOSES 2.2 uses an effective albedo for the urban canyon tile. Here the approach of Harman et al. (2004) is used, which is a function of the height: width ratio and the time of the year for the latitude of each site. In both cases, the low value of the albedo for the road has a significant weighting on the effective albedo, resulting in values of 0.06 for Me93 and 0.10 for $\mathrm{V} 192$.

The results from these simulations are shown in Figure 6, along with the single and two-tile solutions. The lower values of the albedo for the urban canyon result in a larger amplitude for the net radiation, giving a more accurate diurnal range at both the Vancouver and Mexico City locations. For the sensible heat flux, the increase in available energy leads to larger values of the sensible heat flux. This gives an improvement for the magnitude of the flux compared to the observations for the Mexico City site, but results in a flux that is too large at the Vancouver site. At both sites the phase error still exists and is actually enhanced at the Mexico City site.

\subsection{Moisture fluXes}

The simulated and observed moisture fluxes $\left(\mathrm{Q}_{\mathrm{E}}\right)$ are shown in Figure 7. There was no rainfall or snowfall during the observational period at either of the sites, implying that MOSES 2.2 cannot simulate a flux of moisture from the urban tile, since evaporation can only occur if there is water available at the surface (i.e., after precipitation) and not from the soil moisture store. Hence any modelled evaporation can only arise from the small fractions of either vegetation or bare soil. At the time of the observations at both sites, the vegetation was moisture stressed and so the resultant modelled moisture flux at both sites is significantly underestimated compared to the observed flux. The roughness length $\left(z_{0 \mathrm{~m}}\right)$ values used for grass $(0.1 \mathrm{~m})$ and trees $(1.25 \mathrm{~m})$ are the MOSES 2.2 default values. Changing these values to the urban aerodynamic roughness length for each site results in a change in both latent and sensible heat fluxes. For grass, at both sites, the roughness is increased resulting in a reduction in $\mathrm{Q}_{\mathrm{E}}$ due to lower surface temperature and reduced vapour pressure gradient.

However, the result is reversed between the two sites for trees because of the relative size of the urban roughness length to that for trees. In Me93, where $z_{0 \mathrm{~m}}$ is increased for trees, there is a reduction in latent heat flux, whereas for V192 the tree $z_{0 \mathrm{~m}}$ value is reduced, resulting in an increase in 

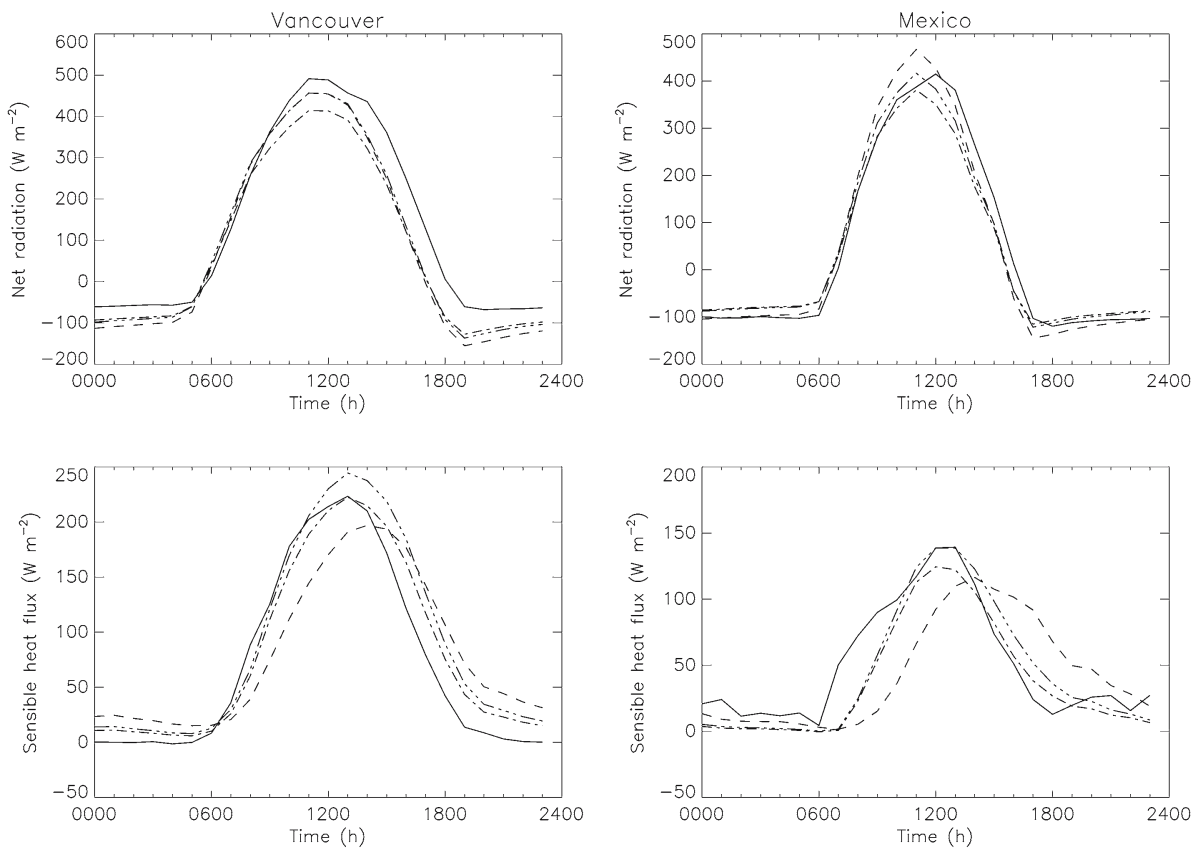

Figure 6. Impact of using an effective albedo for the canyon tile to represent the geometry of the different urban areas. Solid line: observed flux; dotted line: standard one urban tile; dashed dot line: roof and canyon tiles with default albedos; dashed treble dot line: roof and canyon tiles with albedos depending on urban geometry.

$\mathrm{Q}_{\mathrm{E}}$. The net overall impact is a reduction in latent heat flux at both sites because of the relative weighting of vegetation fractions. The relative sizes of these changes are negligible and hence are not shown.

To see if MOSES 2.2 can simulate the observed moisture fluxes, a number of sensitivity runs were undertaken. First, the vegetative fraction (Table I) was replaced with bare soil, since under stress conditions MOSES 2.2 allows for evaporation from bare soil but not from vegetated surfaces. MOSES 2.2 still significantly underestimates the moisture flux at both sites, even when the soil is saturated. Having saturated soil with the original land cover (i.e., including the fraction vegetation) still does not reproduce the observed moisture flux.

The source areas for turbulent flux measurements vary from hour to hour with changing meteorological conditions. One average surface cover was used in the model evaluations, even though the surface cover influencing the measurements was known to have varied. To investigate the impact of this, the simulations were repeated with the vegetation and bare soil fractions doubled. The urban canyon fraction was reduced accordingly, while the roof fraction was kept constant. Figure 7 shows that even when the non-built fractions are doubled, with soil moisture set at the observed 

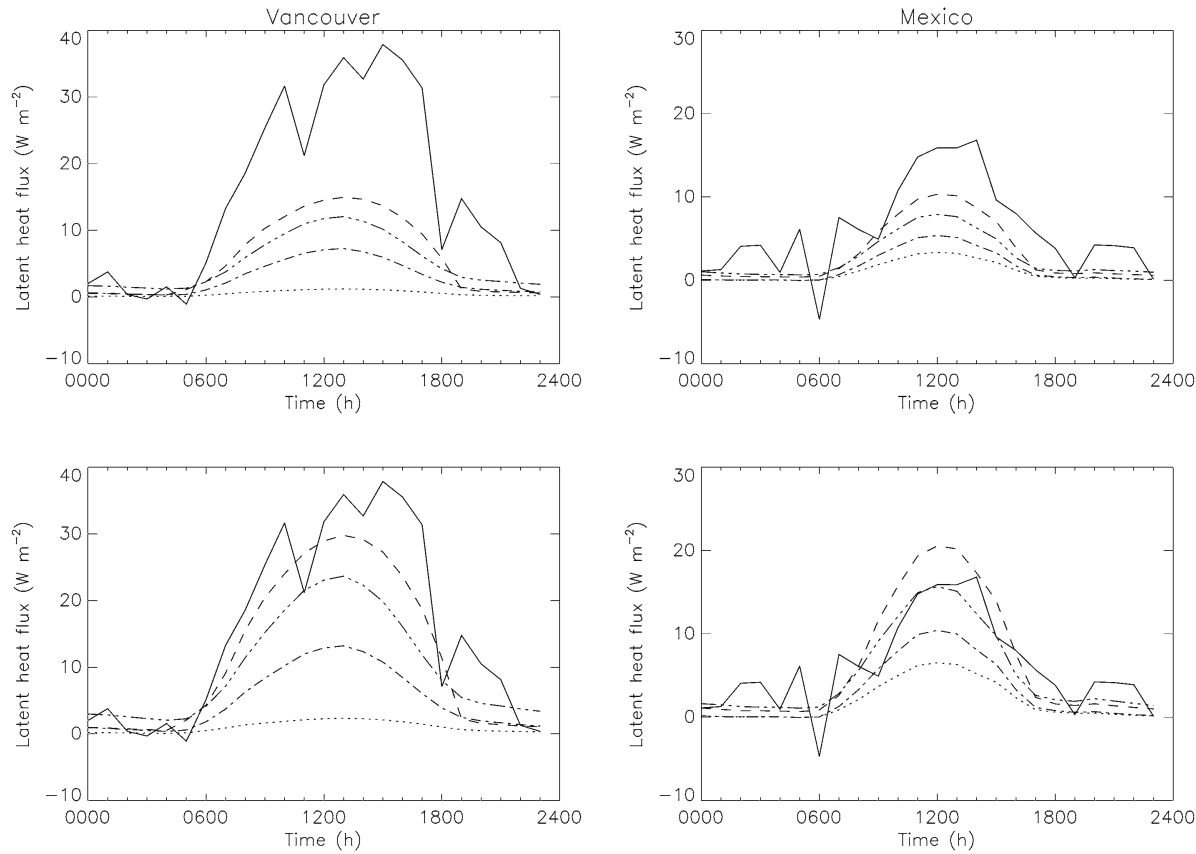

Figure 7. Sensitivity of latent heat flux to fraction of area assigned to vegetated land covers and the soil moisture amount. Lower plots have the vegetated fracts doubled (and the corresponding decrease in urban). Solid line: observed latent heat flux; dotted line: modelled latent heat flux with observed landuse and soil moisture set to observed values; dashed line: modelled latent heat flux with observed landuse and soil moisture set to saturation; dashed dot line: modelled latent heat flux with vegetation replaced by bare soil and soil moisture set to observed values; dashed treble dot line: modelled latent heat flux with vegetation replaced by bare soil and soil moisture set to saturation.

values, compared to the observations MOSES 2.2 still underestimates the latent heat flux at both sites.

For Mexico City the results show that if the entire non-built fraction was saturated bare soil, then the evaporation would be in good agreement with the observations. If vegetation is included with saturated soil, then the modelled evaporation can exceed the observed values. The daily human activity of washing down the streets (which have soil between the cobbles) could be the source of moisture that gives the observed moisture flux at Mexico City, but which cannot be replicated by MOSES 2.2 since there is no anthropogenic source of moisture in a grid cell. This additional anthropogenic water source could be simulated in the current format of MOSES 2.2 by adding saturated bare soil to the fractions of land cover. As noted above, this has been shown to give a good simulation of the observed moisture flux in Mexico City. However, this approach does not work in 


\section{J. BEST ET AL.}

Vancouver, where even doubling the fraction of vegetation and saturating the soil in MOSES 2.2 does not simulate the observed moisture flux.

Clearly there are issues with the flux of moisture that cannot be solved here. The observed moisture flux has a significant magnitude, which cannot be properly represented by MOSES 2.2 with its small fraction of vegetation and bare soil, without setting unrealistic conditions.

\section{Discussion}

A summary of the results presented here is given in Figure 8. The results for the moisture flux show that the model simulations give similar results, with all simulations significantly underestimating the observed flux. For the turbulent sensible heat flux, Figure 8 shows that, compared to the observations, little improvement is obtained when using the observed parameters compared to the MOSES 2.2 default values, but significant improvements are gained when the ratio of the roughness lengths for heat and momentum is reduced to a value of around $10^{-7}$. Additional improvements also result when using two surfaces to represent the urban fraction rather than one, i.e., the fraction of roofs and the fraction of canyons. Using an effective albedo to represent the geometry of the urban areas gives mixed results in terms of additional improvements to the simulations. Figure 9 shows the bias and root-mean-square errors (rmse) for these simulations compared to the observations.

The results are not so clear for the net radiation, where the changes improve the results for Mexico City, but increase the errors for Vancouver. Only the runs with effective albedo, which incorporate some of the effects of urban canyons, actually reduce the errors at both locations. This implies that there is no simple change that can be made to the urban canopy scheme that will improve the simulation of net radiation for both sites, without including some representation of urban geometry.

The increased errors in the other fluxes at both sites with the effective albedo suggest that, although this is an improvement to the urban canopy scheme since it introduces the presence of urban canyons into the model structure, the influence of the geometry on other model parameters (such as the effective heat capacity) also needs to be included.

The performance statistics for MOSES 2.2 show that the urban surface scheme performs better at the Mexico City site than at the Vancouver site (Figure 9, run d). The absolute daytime errors are generally larger than the errors at night, but this is to be expected as the daytime fluxes have a greater magnitude (the relative nighttime errors are greater). The magnitudes of the errors with the simulations are comparable to those obtained with the more complex TEB model of Masson et al. (2002), with the net 
EVALUATION OF THE URBAN TILE IN MOSES
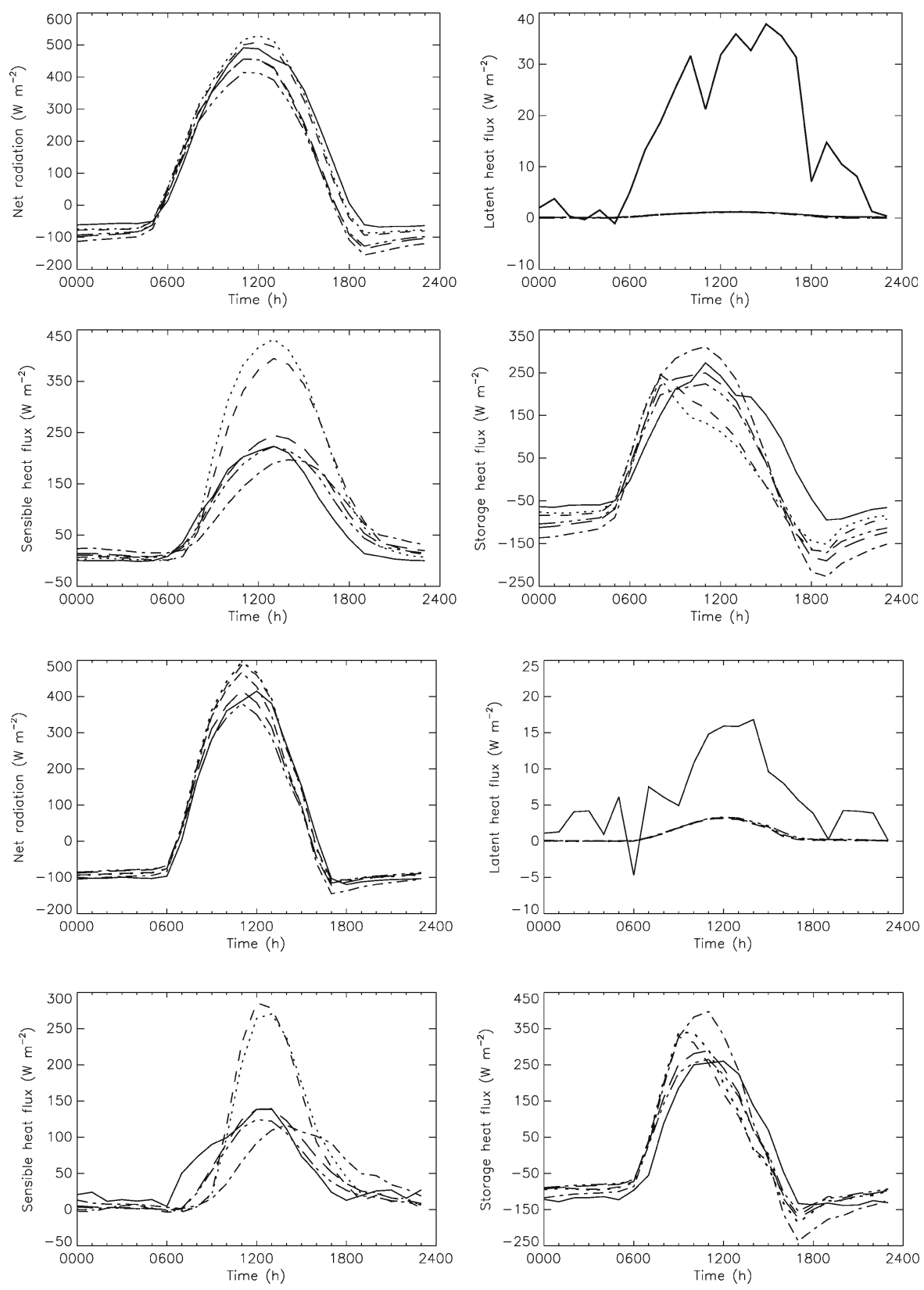

Figure 8. Summary of model results. Solid line: observed flux; dotted line: default model parameters; short dashed line: observed values for model parameters; dashed dot line: $z_{0 t} / z_{0 \mathrm{~m}}=10^{-7}$; dashed treble dot line: roof and canyon tiles with default albedos; long dashed line: roof and canyon tiles with albedos depending on urban geometry. (a) Vancouver; (b) Mexico City. 
M. J. BEST ET AL.
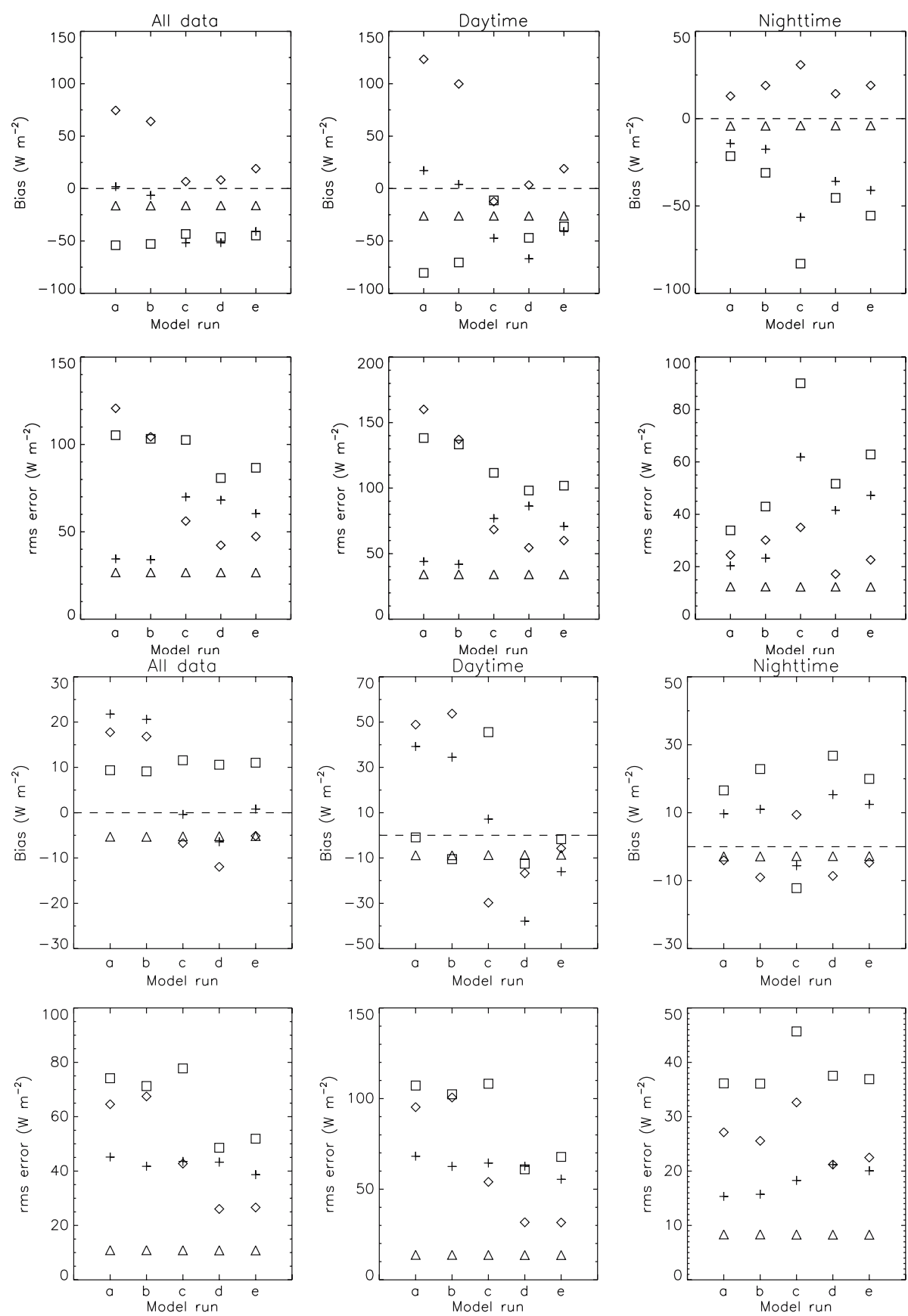

Figure 9. Model errors (bias and rmse) of energy balance terms, run a default parameters, run $\mathrm{b}$ observed parameters, run $\mathrm{c} z_{0 \mathrm{t}} / z_{0 \mathrm{~m}}=10^{-7}$, run $\mathrm{d}$ roof and canyon tiles, run e effective albedo. Cross: net radiation, diamond: sensible heat flux, triangle: latent heat flux, square: heat storage. (a) Vancouver; (b) Mexico city. 
radiation errors being slight poorer, but the sensible heat flux errors being slightly better, and the heat storage errors being approximately the same. This shows that, although the urban canopy scheme does not give a perfect simulation at both sites, it can capture some of the elements of a more complex model.

Visual inspection of the time series for the Mexico City site (Figure 10) shows that MOSES 2.2 represents the fluxes reasonably well on an hourto-hour basis, with the exception of the moisture flux. However, there are a couple of points to note with respect to the turbulent sensible heat flux. The early morning increase in the observed turbulent heat flux is not captured by MOSES 2.2. The larger nocturnal fluxes that occur during the second half of the period, also are not captured by MOSES 2.2. As noted earlier, anthropogenic heat is not accounted for in MOSES 2.2 but this would be expected to have its greatest impact in the late afternoon and early morning.

For Vancouver, there are a number of days where the modelled turbulent sensible heat flux is in good agreement with the observations. However, MOSES 2.2 does not capture the 2 or 3 days near the end of the period when the daytime observed fluxes are significantly higher. During this period the net radiation did not significantly change.

For the net radiation at the Vancouver site, there seems to be a consistent offset in MOSES 2.2 of approximately $50 \mathrm{~W} \mathrm{~m}^{-2}$, suggesting a problem with the modelled longwave radiation, since errors in the solar radiation would have a diurnal signal. However, since the solar radiation was measured at locations $10 \mathrm{~km}$ away from the observational site, and the incoming longwave radiation is calculated from an empirical formula, it is not possible to investigate the problems with the model net radiation any further due to the uncertainty in the spatial mismatch of the observations.

When interpreting the results presented here, it is important to remember that these simulations are off-line, i.e. the surface scheme is not coupled to an atmospheric model. This means that the interaction between the near-surface temperature and the surface heat fluxes is not accounted for. Thus, while the derived surface fluxes are controlled by the atmospheric temperature, the atmospheric temperature is not influenced by the surface flux, which should feed back onto the surface fluxes. Such interactions are included in more dynamic coupled models.

Errors identified in off-line simulations may indicate areas that need improvement within a surface model. However, in a coupled framework, these errors (such as phase errors) may be reduced to a level where they are smaller than other errors within the coupled system. This means that for some practical applications, such as weather forecasting, improvements to the surface scheme within a coupled environment may not be justified. However, it also implies that caution needs to be used when applying 
M. J. BEST ET AL.
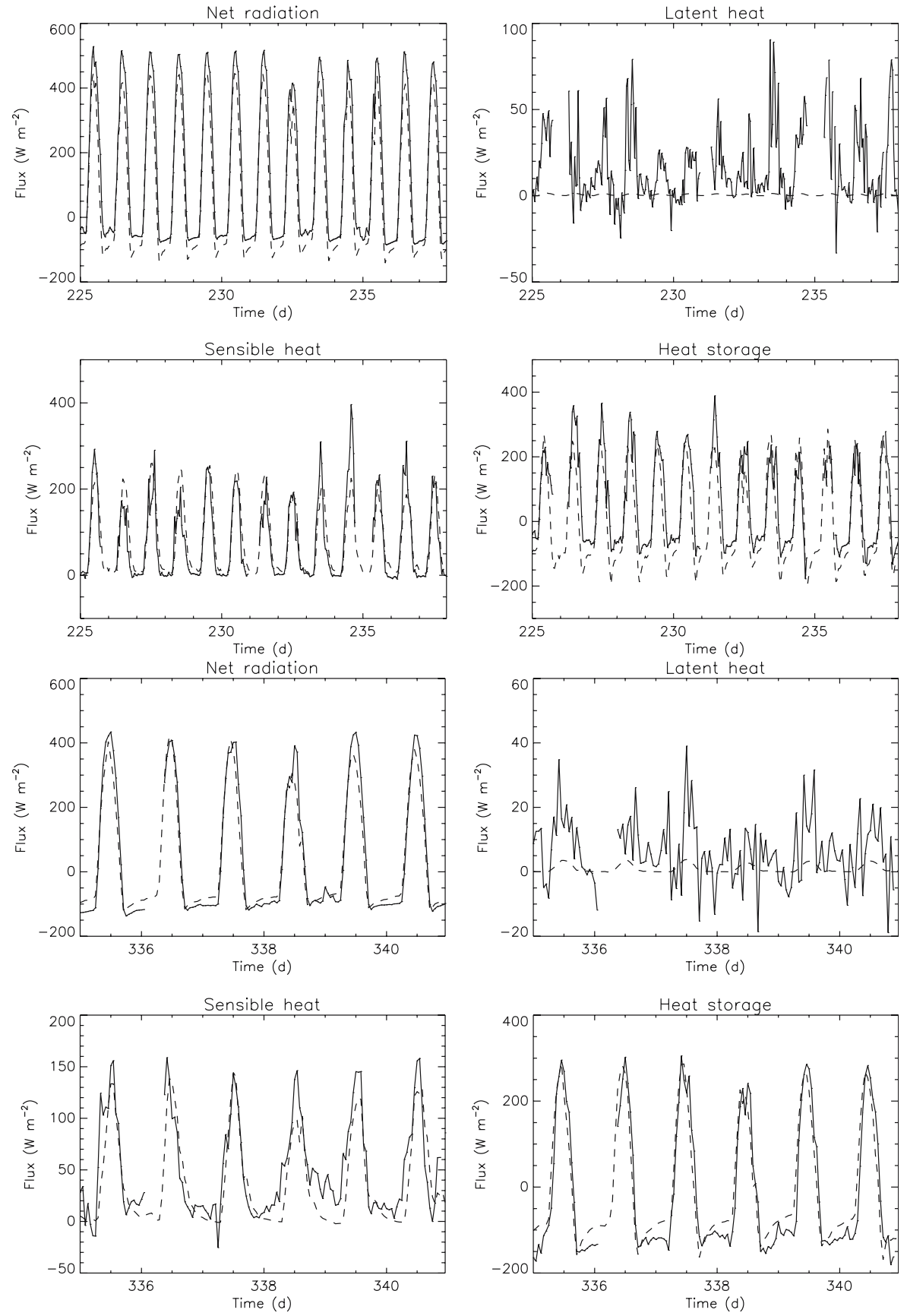

Figure 10. Hourly time series of observed and modelled (roof and canyon tile model) energy balance fluxes; Solid line: observed flux; dashed line: modelled flux. (a) Vancouver; (b) Mexico city. 
a land surface scheme in a non-tested coupled model set-up because of the role of feedback between schemes. As the observations are not all co-located, and all observational data have measurement errors associated with them, it is also important to recognise that a perfect match to any model is not expected. This may well explain some of the differences seen between the results presented in this study and the results presented in Best (2005b), which suggested that the basic canopy scheme did not need much improvement. However, it should be noted that the results presented in Best (2005b) only considered the impact on screen level temperature, so we cannot carry out a comprehensive coupled/uncoupled comparison.

To have a more complete understanding of the behaviour and the evaluation of an urban model, the scheme needs to be tested in a coupled framework and in off-line simulations. This is difficult because the system needs to be constrained enough to separate out the errors from the atmospheric model and the errors from the surface scheme. To do this we would need a comprehensive observational dataset of which there are few that exist at present.

\section{Conclusions and Recommendations}

Based on the evaluation presented here, we conclude that the basic canopy scheme in MOSES 2.2 does not adequately capture the physical processes of the urban atmosphere to accurately represent an urban area. Results indicate that separate canyon and roof fractions significantly improve the simulation. In addition, results suggest that the ratio for the roughness lengths for heat and momentum for urban areas is of the order of $10^{-7}$.

In response to this study, it is apparent that surface schemes also need to be coupled to boundary-layer schemes for comparisons with observations to understand more fully their behaviour. It has been demonstrated here, relative to Best (2005b), that model performance is dependent on the mode in which the model is run and the meteorological variables considered.

\section{Acknowledgements}

The support of the National Science Foundation BCS-0095284 (SG) is gratefully acknowledged. Solar radiation data for Mexico City were supplied by Dr. Agustín Muhlia Velázquez, Coordinador del Observatorio de Radiación Solar, Instituto de Geofísica, UNAM.

Those who contributed to the observations at the two sites, in particular Ernesto Jauregui (UNAM), Rachel Spronken-Smith (Otago), and Tim Oke (UBC) are gratefully acknowledged. 


\section{J. BEST ET AL.}

\section{References}

Arnfield, A. J.: 2003, 'Two Decades of Urban Climate Research: A Review of Turbulence, Exchanges of Energy and Water, and the Urban Heat Island', Int. J. Climatol. 23, 1-26.

Arnfield, A. J. and Grimmond, C. S. B.: 1998, 'An Urban Canyon Energy Budget Model and its Application to Urban Storage Heat Flux Modelling', Energy Build. 27, 61-68.

Best, M. J.: 1998, 'Representing Urban Areas in Numerical Weather Prediction Models', Second Symp. Urban Environ. Amer. Meteorol. Soc. 148-151.

Best, M. J.: 2000, 'Can We Represent Urban Areas in Operational Numerical Weather Prediction Models?', Third Symp. Urban Environ. Amer. Meteorol. Soc. 70-71.

Best, M. J. and Clark, P. A.: 2002, 'The Influence of Vegetation on the Urban Climate', Fourth Symp. Urban Environ. Amer. Meteorol. Soc. 88-89.

Best, M. J.: 2005a, 'Progress Towards Better Weather Forecasts for City Dwellers: From Short Range to Climate Change', Theor. Appl. Climat., in press.

Best, M. J.: 2005b, 'Representing Urban Areas Within Operational Numerical Weather Prediction Model', Boundary-Layer Meteorol. 114, 91-109.

Essery, R. L. H., Best, M. J., Betts, R. A., Cox, P. M., and Taylor, C. M.: 2003, 'Explicit Representation of Subgrid Heterogeneity in a GCM Land Surface Scheme', J. Hydrometeorol. 4, 530-543.

Grimmond, C. S. B.: 2005, 'Progress in Measuring and Observing the Urban Atmosphere', Theor. Appl. Climat. in press.

Grimmond, C. S. B. and Oke, T. R.: 1999a, 'Heat Storage in Urban Areas: Observations and Evaluation of a Simple Model', J. Appl. Meteorol. 38, 922-940.

Grimmond, C. S. B. and Oke, T. R.: 1999b, 'Aerodynamic Properties of Urban Areas Derived from Analysis of Surface Form', J. Appl. Meteorol. 38, 1262-1292.

Grimmond, C. S. B. and Oke, T. R.: 2002, 'Turbulent Heat Fluxes in Urban Areas: Observations and Local-Scale Urban Meteorological Parameterization Scheme (LUMPS)', J. Appl. Meteorol. 41, 792-810.

Harman, I. N., Best, M. J. and Belcher, S. E.: 2004, 'Radiative Exchange in an Urban street Canyon', Boundary-Layer Meteorol. 110, 301-316.

Herbert, J. M., Johnson, G. T., and Arnfield, A. J.: 1998, 'Modelling the Thermal Climate in City Canyons', Environ. Model. Software 13, 267-277.

Lemonsu, A., Grimmond, C. S. B., and Masson, V.: 2004, 'Modelling the Surface Energy Balance of an old Mediterranean city core', J. Appl. Meteorol. 43, 312-327.

Martilli, A., Clappier, A., and Rotach, M. W.: 2002, 'An Urban Surface Exchange Parameterisation for Mesoscale Models', Boundary-Layer Meteorol. 104, 261-304.

Masson, V.: 2000, 'A Physically-Based Scheme for the Urban Energy Budget in Atmospheric Models', Boundary-Layer Meteorol. 94, 357-397.

Masson, V.: 2005, 'Progress in Urban Surface Modeling and the Meso-scale Impact of Cities', Theor. Appl. Climat. in press.

Masson, V., Grimmond, C. S. B., and Oke, T.R.: 2002, 'Evaluation of the Town Energy Balance (TEB) Scheme with Direct Measurements from Dry Districts in Two Cities', J. Appl. Meteorol. 41, 1011-1026.

Mills, G.:1997, 'The Radiative Effects of Building Groups on Single Structures', Energy Build 25, 51-61.

Oke, T. R.: 1988, 'The Urban energy Balance', Prog. Physical Geog. 12, 471-508.

Oke, T. R., Cleugh, H. A., Grimmond, C. S. B., Schmid, H. P., and Roth, M.: 1989, 'Evaluation of Spatially-Averaged Fluxes of Heat, Mass and Momentum in the Urban Boundary Layer', Weather Climate 9, 14-21. 


\section{EVALUATION OF THE URBAN TILE IN MOSES}

Oke, T. R., Spronken-Smith, R., Jauregui, E., and Grimmond, C. S. B.: 1999, 'Recent Energy Balance Observations in Mexico City', Atmos. Environ, 33, 3919-3930.

Plate, E. J.: 1999, 'Methods of Investigating Urban Wind Fields - Physical Models', Atmos. Environ, 33, 3981-3989.

Prata, A. J.: 1996, 'A new Longwave Formula for Estimating Downward Clear-sky Radiation at the Surface', Quart. J. Roy Meteorol. Soc. 122, 1127-1151.

Schmid, H. P.: 1994, 'Source Areas for Scalars and Scalar Fluxes', Boundary-Layer Meteorol. 67, 293-318.

Voogt, J. A. and Grimmond, C. S. B.: 2000, 'Modeling Surface Sensible Heat Flux Using Surface Radiative Temperatures in a Simple Urban Area', J. Appl. Meteorol, 39, 16791699. 